\title{
(60)Flow Analysis and Experiment of Pressure-regulating Valve Used in Wet Friction Clutch
}

\author{
Jianchun Gong ${ }^{1, a}$ Zeyin $\mathrm{He}^{2, \mathrm{~b}}$ \\ ${ }^{1}$ PanZhiHua University, Sichuang, china ,617000 \\ 2 State Key Laboratory of Mechanical Transmission,Chongqing University, china ,400030 \\ ajcgong01@163.com , b313778475@qq.com
}

\begin{abstract}
Keywords: Marine gearbox; wet friction clutch; pressure-regulating valve; internal flow field; computational fluid dynamics
\end{abstract}

\begin{abstract}
This paper taking a Marine gearbox wet friction clutch hydraulic control system as the main research object. Based on ANSYS established pressure regulating valve inside passage fluid dynamics finite element calculation model, in different flow and import oil temperature respectively under pressure regulating valve in different flow when the latter flow field numerical calculation, get pressure regulating valve inside passage oil temperature, flow and hydraulic valve core, the relationship between the latter; In Marine gearbox comprehensive performance test on the selection of test gear box for pressure regulating valve in different valve core under the latter of different flow rate and different import oil temperature of hydraulic characteristics more sets of test research. Through The test and simulation data contrast, The results show that The data indicates that they are in good agreement, verified The rationality of The numerical calculation method of large secondary pressure regulating valve flow field simulation, oil pressure test and pressure regulating valve port structure improvement provides certain reference.
\end{abstract}

\section{Introduction}

The clutch absorbs kinetic energy of propeller through friction slip because there is a difference in the propeller speed and rotational speed of diesel engine speed at the initial stage of the clutch reversing binding with a wet friction clutch of marine gearbox. To ensure the secure transmission torque of clutch, the torque should be immediately rise to diesel engine rated torque over 1.5 times when the clutch slips at the end ${ }^{[1]}$, in order to keep the clutch connection row state, oil should be immediately rose to clutch the required high pressure when the process is completed of clutch connected, which requires the clutch connected with a row of early low oil pressure. The second stage pressure regulating valve can be used to make the clutch to low oil pressure switch, with half a slipping state transfer part load, then the oil pressure increases of pressure regulating valve in the setting of time, which makes the clutch engaged the diesel engine power transfer to the propeller ${ }^{[2]}$. With the trend of the large-scale development of marine gear box, the higher requirement of hydraulic system control precision with wet friction clutch is put forward. Therefore, it is necessary to research on pressure regulation valve flow characteristics in theory and test. In recent years, CFD technology is widely used in flow field of numerical simulation ${ }^{[3-8]}$. But the ship ellipsoidal valve pressure regulating valve internal flow field simulation and experimental research is relatively rare.

We have employed the experiment and numerical simulation method to study the marine pressure regulating valve of pressure characteristics, and got the pressure regulating valve flow valve the opening of the oil temperature, oil pressure, flow rate and the relationship between the marine gear box through the calculating the spool opening different inlet temperature under different flow rates, respectively on the pressure within the valve flow field in different degrees by using the ANSYS to build pressure regulating valve internal flow passage of fluid dynamics finite element analysis model. We have selected 10 same types of test of gear box pressure regulation valve in different valve opening of the comprehensive performance test bench in different inlet oil temperature, oil pressure characteristics under different flow rates. 


\section{Mathematical Model for Pressure Regulating Valve of Internal Flow Field}

Fluid Control Equation.Fluid dynamics equations of pressure regulating valve in flow channel include continuity equation, momentum equation and energy conservation equation.

Turbulent Transport Equation. To solve fluid control equation of pressure regulating valve internal flow passage, it is needed to complement the reaction characteristics of turbulent flow energy equation and turbulent dissipation equation. Based on the pressure regulating valve flow channel structure, using RNG $k-\varepsilon$ two equation turbulence models, kinetic energy equation and kinetic energy dissipation rate equation can be respectively described as follows:

$$
\begin{array}{lr}
\frac{\partial \rho k}{\partial t}+\frac{\partial\left(\rho v_{x} k\right)}{\partial x}+\frac{\partial\left(\rho v_{y} k\right)}{\partial y}+\frac{\partial\left(\rho v_{z} k\right)}{\partial z}=\frac{\partial}{\partial x}\left(\frac{\mu_{t}}{\sigma_{k}} \frac{\partial k}{\partial x}\right) & (\text { Eq. } 1) \frac{\partial \rho \varepsilon}{\partial t}+\frac{\partial\left(\rho v_{x} \varepsilon\right)}{\partial x}+\frac{\partial\left(\rho v_{y} \varepsilon\right)}{\partial y}+\frac{\partial\left(\rho v_{z} \varepsilon\right)}{\partial z}=\frac{\partial}{\partial x}\left(\frac{\mu_{t}}{\sigma_{\varepsilon}} \frac{\partial \varepsilon}{\partial x}\right) \\
+\frac{\partial}{\partial y}\left(\frac{\mu_{t}}{\sigma_{k}} \frac{\partial k}{\partial y}\right)+\frac{\partial}{\partial z}\left(\frac{\mu_{t}}{\sigma_{k}} \frac{\partial k}{\partial z}\right)+\mu_{t} \phi-\rho \varepsilon & +\frac{\partial}{\partial y}\left(\frac{\mu_{t}}{\sigma_{\varepsilon}} \frac{\partial \varepsilon}{\partial y}\right)+\frac{\partial}{\partial z}\left(\frac{\mu_{t}}{\sigma_{\varepsilon}} \frac{\partial \varepsilon}{\partial z}\right)+C_{1 \varepsilon} \mu_{t} \frac{\varepsilon}{k} \phi-C_{2} \rho \frac{\varepsilon^{2}}{k}
\end{array}
$$

Where $k$ is turbulent kinetic energy; $\varepsilon$ is turbulence kinetic energy dissipation rate; $\mu_{t}$ is turbulent viscosity, $\mu_{t}=\rho C_{\mu} k^{2} / \varepsilon ; \mathrm{C}_{\mu} 、 C_{1 \varepsilon} 、 C_{2}$ are constants of turbulent model of RNG $k-\varepsilon ; \phi$ is viscous dissipation; $\sigma_{k} 、 \sigma_{\varepsilon}$ are value of Prandtl of turbulent kinetic energy and turbulence kinetic energy dissipation rate. $C_{\mu}=0.085, C_{1 \varepsilon}=1.42, C_{2}=1.68, \sigma_{k}=\sigma_{\varepsilon}=0.72^{[10-12]}$ 。 And then we can calculate the six parameters $p 、 v_{x}, v_{y}, v_{z}, k, \varepsilon$.

\section{Structures, Working Process and Principle of Second Level Pressure Regulating Valve}

Pressure regulating valve assembly diagram is mainly composed of a valve body, valve core, a spring, a booster piston. The profile curve equation is typical ellipse. In order to let the clutch connected stably, there is a certain opening degree existed between the valve core in the work of the initial position and the valve orifice as shown in Fig.1.

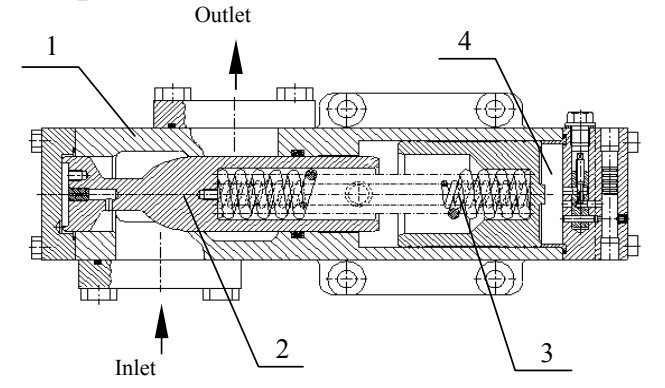

1.valve body, 2.valve core, 3.spring, 4.boosting piston

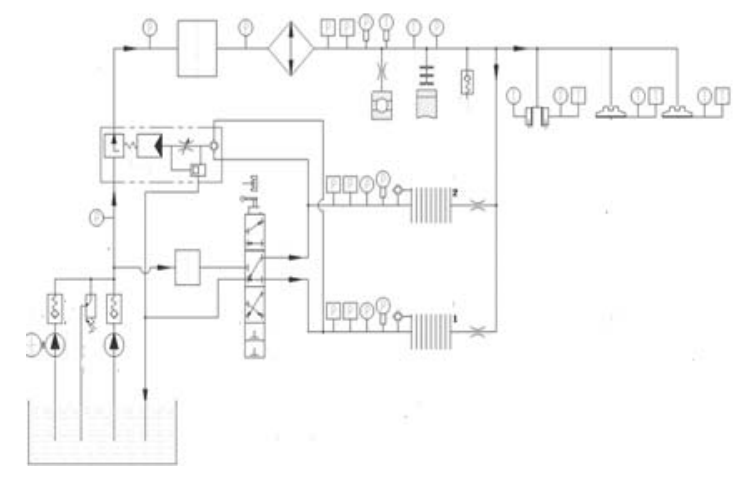

Fig.2 Gear box hydraulic system diagram

Fig.1 Assembly structure diagram of pressure regulating valve

The marine gear box hydraulic system diagram is shown as Fig.2. the main work process of the gear box hydraulic system pressure regulating valve is the connection between the booster piston oil inlet and clutch cylinder oil inlet cavity, when the control valve is adjusted to the connected row position, inlet oil liquid of second level pressure regulating valve press the friction plate and dual plate through a control valve, at the same time the oil was injected into the second pressure regulator valve for supercharging.

Pressure regulating valve is mainly composed of a shuttle valve, hydraulic control valve delay valve, etc., and it plays a set of hydraulic system oil and lubricating oil pressure and flow in the clutch hydraulic control system, high pressure oil is used for clutch piston control, and low pressure of lubricating oil for lubrication and cooling of gear box includes a clutch.

\section{Flow Field Simulation and Analysis}


The Finite Element Analysis Model.The model of ellipsoidal valve internal flow passage has been established based on using Fluid 142unit on the entity model finite element grid discretization as shown in figure 3. Hydraulic oil is adopted CD40GB11122 diesel engine oil, assuming that the fluid and wall contact boundary is the static adiabatic wall; the outlet pressure is $0.3 \mathrm{MPa}$.

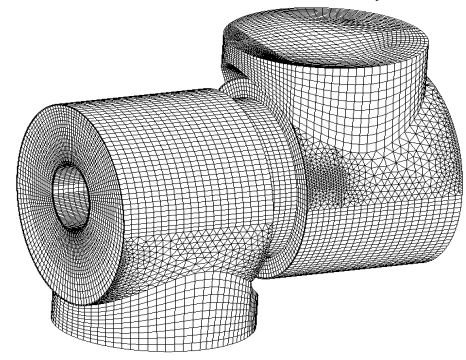

Fig. 3 The model of ellipsoidal valve internal flow passage

The Simulation of Different Flow Field.Working pressure valve inlet flow have been analyzed respectively $370 \mathrm{~L} / \mathrm{min}, 630 \mathrm{~L} / \mathrm{min}$. The internal flow field has been calculated at different pressure regulating valve opening degree when the inlet oil temperature is $58 \mathrm{DEG} \mathrm{C}$. The pressure valve flow passage pressure contour is shown as figure 4 under the condition of $0.895 \mathrm{~mm}$ opening degree and $630 \mathrm{~L} / \mathrm{min}$ inlet flow rate.

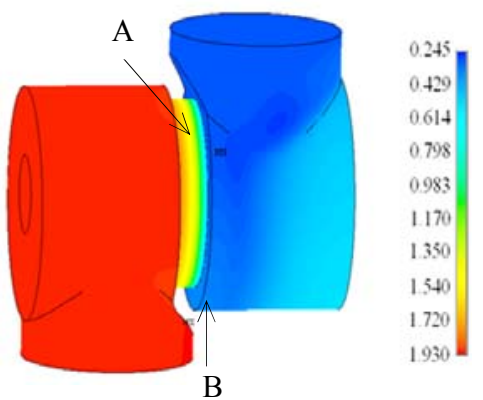

Fig.4 pressure contour under the condition of $0.895 \mathrm{~mm}$ opening degree and $630 \mathrm{~L} / \mathrm{min}$ inlet flow rate

Figure 5 gives $\mathrm{P}$ curve under the different discharge valve internal flow passage of fluid pressure with the opening of the $\delta$.

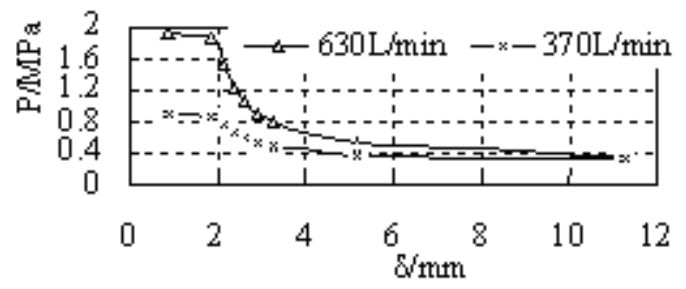

Fig. $5 P-\delta$ curve under the different flow

Figure 6 gives velocity $\mathrm{V}$ curve under the different discharge valve internal flow passage of fluid pressure with the opening of the $\delta$.

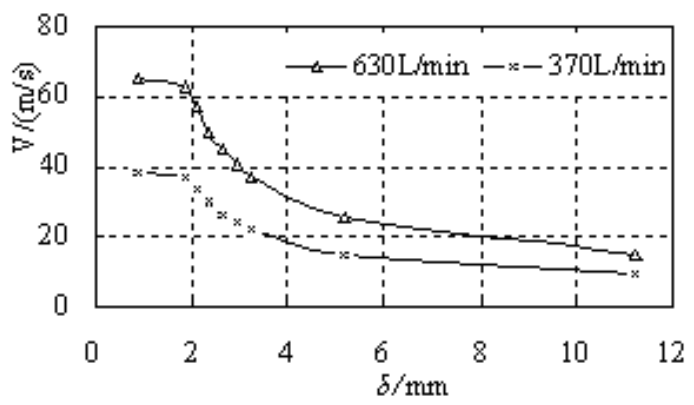

Fig. $6 \mathrm{~V}-\delta$ curve under the different flow 
Based on figure 4 to 6 , we can conclude that the pressure gradient become large due to the decreased flow passage when the fluid from the valve opening A; It is easy to produce cavitation in the valve jitter when the lower pressure appears in the valve $\mathrm{B}$ in the process of valve core movement; The largest pressure is $0.93 \mathrm{MPa}$ when the flow rate $370 \mathrm{~L} / \mathrm{min}$; The largest pressure is $1.93 \mathrm{MPa}$ when the flow rate $630 \mathrm{~L} / \mathrm{min}$; The change rule of $\mathrm{V}-\delta$ and $\mathrm{P}-\delta$ are consistency under the condition of different flow; the maximum pressure and velocity decreases rapidly When the ellipsoidal pressure regulating valve opening degree is small and with the opening of the increase; Curve change is smooth when the opening is larger than $4 \mathrm{~mm}$.

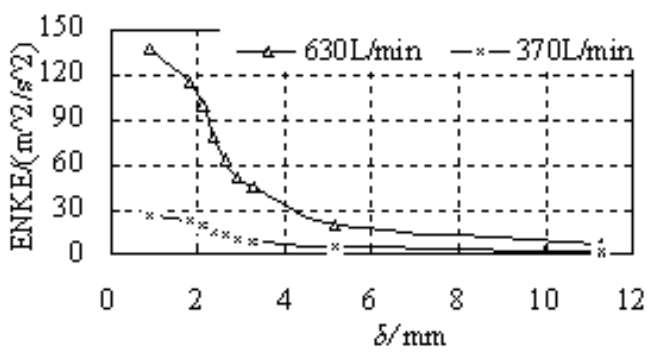

Fig. 7 ENKE- $\delta$ curve under different flow

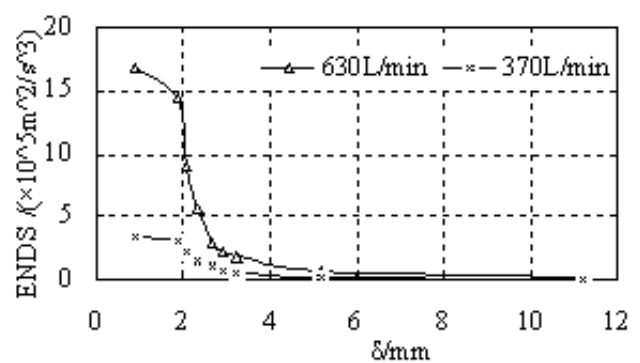

Fig. 8 ENDS- $\delta$ curve under different flow

For further analysis of valve flow passage fluid kinetic energy and kinetic energy dissipation, ENKE- $\delta$ and ENDS- $\delta$ curves under different flow as shown in Figure 7 and Figure 8.

The Flow Simulation of Different Temperature of Inlet Oil.Internal flow field has been calculated under the different opening degree of pressure regulating valve when inlet oil temperature are respectively $40^{\circ} \mathrm{C}, 50^{\circ} \mathrm{C}$ and $70^{\circ} \mathrm{C}$; inlet flow rate is $630 \mathrm{~L} / \mathrm{min}$. When opening degree is $0.895 \mathrm{~mm}$ and inlet oil temperature is $40^{\circ} \mathrm{C}$, the pressure contour of pressure regulating valve flow passage is shown in figure 9.

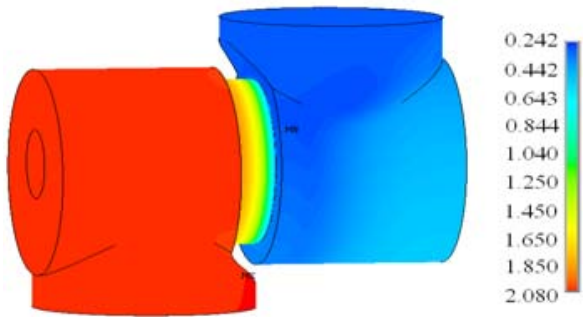

Fig.9 pressure contour (opening degree is $0.895 \mathrm{~mm}$, inlet oil temperature is $40^{\circ} \mathrm{C}$

Figure 10 gives the largest pressure $\mathrm{P}$ curve under the different inlet oil temperature valve internal flow passage of fluid pressure with the opening of the $\delta$.

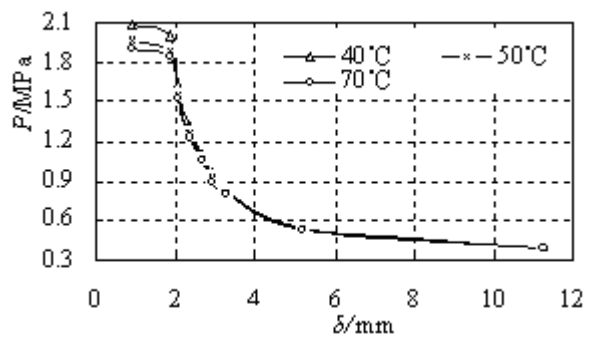

Fig.10 $P-\delta$ curve under different inlet oil temperature

Table 1 gives the maximum hydraulic simulation value under the different inlet oil temperature when the opening degree is $0.895 \mathrm{~mm}$.

Table. 1 hydraulic value under different inlet oil temperature

\begin{tabular}{ccccc} 
Oil temperature $\left({ }^{\circ} \mathrm{C}\right)$ & 40 & 50 & 60 & 70 \\
\hline $\begin{array}{c}\text { Maximum } \\
\text { pressure }(\mathrm{MPa})\end{array}$ & 2.08 & 1.97 & 1.93 & 1.91 \\
\hline
\end{tabular}


Figure 11 gives maximum velocity $\mathrm{V}$ curve under the different inlet oil temperature valve internal flow passage of fluid pressure with the opening of the $\delta$.

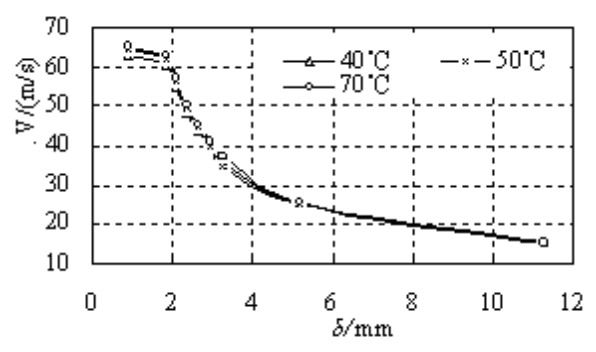

Fig. $11 V-\delta$ curve under the different inlet oil temperature

Based on figure 9 to 11 , we can learn that the change rule of $V-\delta$ and $P-\delta$ are consistency under the condition of different inlet oil temperature; the maximum pressure and velocity decreases rapidly When the ellipsoidal pressure regulating valve opening degree is small and with the opening of the increase; Curve change is smooth when the opening is larger than $4 \mathrm{~mm}$; the pressure $\mathrm{P}$ and velocity $\mathrm{V}$ become large with the inlet oil temperature increased; the maximum oil pressure is reduced by $9 \%$ when the temperature dropped from $70^{\circ} \mathrm{C}$ to $40^{\circ} \mathrm{C}$.

For further analysis of valve flow passage fluid kinetic energy and kinetic energy dissipation, ENKE- $\delta$ and ENDS- $\delta$ curves under different inlet oil temperature as shown in Figure 12 and Figure 13.
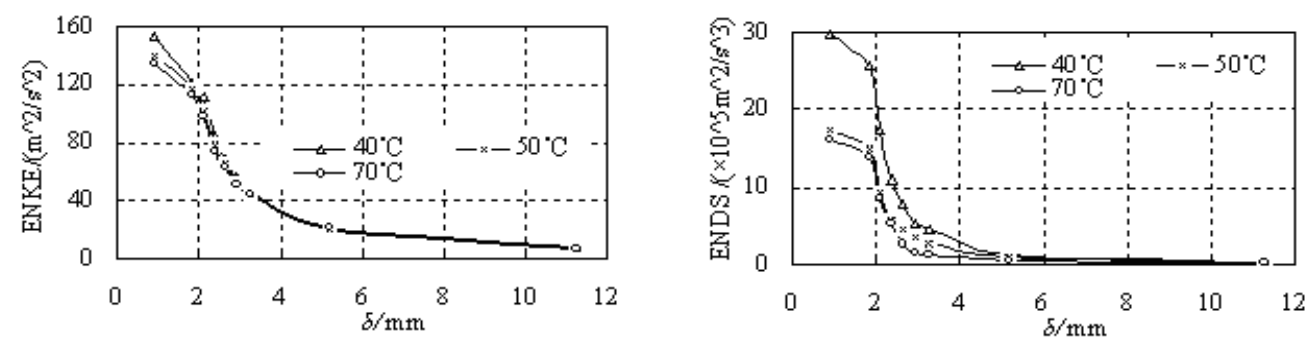

Fig.12 ENKE $-\delta$ curve under different oil temperature Fig.13 ENDS- $\delta$ curve under different oil temperature

Based on figure 12 to 13 , we can assert that the change rule of $E N K E-\delta$ and $E N D S-\delta$ are consistency under the condition of different inlet oil temperature; the maximum ENKE、ENDS decreases rapidly When the ellipsoidal pressure regulating valve opening degree is small and with the opening is around 2mm; Curve change is smooth when the opening is larger than 4mm; when the inlet oil temperature is around $40^{\circ} \mathrm{C}$, internal flow fluid kinetic energy dissipation become large, therefore, it is strict to control the oil temperature of the system.

\section{Pressure Regulating Valve Hydraulic Performance Test}

The hydraulic test is take place in the marine gear box integrated performance testing station. And the integrated performance station is composed of hydraulic dynamometer, gear box, universal coupling test, DC motor and hydraulic station, as shown in figure 14.

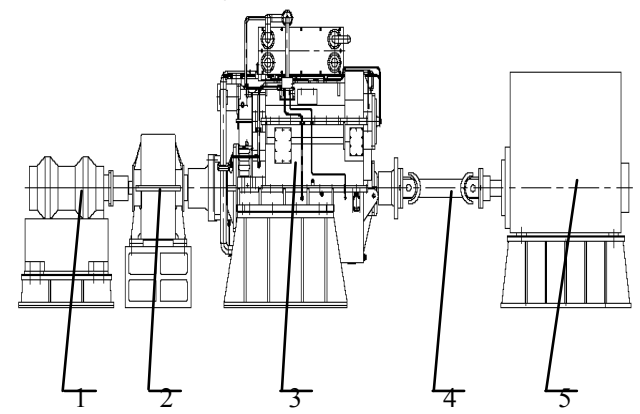

1 hydraulic dynamometer, 2 gear box, 3 test gear box, 4 universal coupling test, 5 DC motor 
Fig.14 Marine gearbox test-bed structure diagram

The gear test box contains two sets of wet multi-plate friction clutch and a second level pressure regulating valve. The test load is produce by hydraulic dynamometer and DC by control station. The second level pressure regulating valve is installed in the test in the gear box, and it is mainly used for multi-plate friction clutch hydraulic control and for the entire test gear box lubrication oil.

Oil temperature is test by the temperature sensor. Pressure of working oil is test by pressure sensor. And flow meter is used for determination of oil flow. The CD40 GB11122 diesel engine oil is adopted, second level pressure regulating valve oil flow is supplied by gear box machine oil pump. Pressure regulating valve is acquired and processed by oil pressure test system.

Oil Pressure Test of Pressure Regulating Valve. When we test the oil pressure, the oil temperature is stable at $58^{\circ} \mathrm{C}$ through controlling the inlet quantity of gear box cooler water. Opening degree is achieved through the clutch of two different receiving and discharging speed and the gear box with sliding pump oil supply. And we test the oil temperature when the flow rate is respectively $370 \mathrm{~L} / \mathrm{min}$ and $630 \mathrm{~L} / \mathrm{min}$, and select the 10 same types of test of gear box dividing into two groups. We test the pressure of regulating valve when the opening degree is respectively $0.895 \mathrm{~mm}$ and $1.86 \mathrm{~mm}$. In order to simulate precisely we acquire the test data of pressure regulating valve of each group contained 5 pressure regulating valves.

Results and relative error of oil pressure and simulation is shown as table 2 and table 3 when the flow rate is respectively $370 \mathrm{~L} / \mathrm{min} 、 630 \mathrm{~L} / \mathrm{min}$ and opening degree is respectively $0.895 \mathrm{~mm}$ and $1.86 \mathrm{~mm}$.

\begin{tabular}{|c|c|c|c|c|}
\hline & & $\begin{array}{l}\text { Simulation } \\
\text { /MPa }\end{array}$ & $\begin{array}{l}\text { Average of } \\
\text { test /MPa }\end{array}$ & $\begin{array}{l}\text { Relative } \\
\text { error\% }\end{array}$ \\
\hline \multirow{2}{*}{$\begin{array}{l}\text { Opening } \\
\text { degree } \\
\delta / \mathrm{mm} \\
\end{array}$} & 0.895 & 0.90 & 0.87 & 3.33 \\
\hline & 1.860 & 0.88 & 0.83 & 5.68 \\
\hline \multicolumn{5}{|c|}{ Table. 3 Oil pressure $(630 \mathrm{~L} / \mathrm{min})(\mathrm{MPa})$} \\
\hline & & $\begin{array}{c}\text { Simulation } \\
\text { /MPa }\end{array}$ & $\begin{array}{c}\text { Average of } \\
\text { test } / \mathrm{MPa}\end{array}$ & $\begin{array}{l}\text { Relative } \\
\text { error \% }\end{array}$ \\
\hline \multirow{2}{*}{$\begin{array}{l}\text { Opening } \\
\text { degree } \\
\delta / \mathrm{mm}\end{array}$} & 0.895 & 1.93 & 1.90 & 1.50 \\
\hline & 1.860 & 1.86 & 1.75 & 5.70 \\
\hline
\end{tabular}

We can see from the table 2 and table3, there have a relative error between the test data and calculating data. It meets the requirement of engineer when the relative error is $5.70 \%$ under the condition that flow rate is respectively $370 \mathrm{~L} / \mathrm{min} 、 630 \mathrm{~L} / \mathrm{min}$.

Oil Pressure Test of Different Oil Temperature and Flow of Regulating Valve.Opening degree of pressure regulating valve is $0.895 \mathrm{~mm}$ under the condition of different oil temperature and flow. We test the pressure of regulating valve based on 10 same typed gear boxes divided into 2 groups.

Table.4 Oil pressure of different oil temperature (MPa)

\begin{tabular}{ccccccc}
\hline $\begin{array}{c}\text { Oil } \\
\text { temperature } /{ }^{\circ} \mathrm{C}\end{array}$ & $\begin{array}{c}\text { 1\#gear } \\
\text { box }\end{array}$ & $\begin{array}{c}2 \# \text { gear } \\
\text { box }\end{array}$ & $\begin{array}{c}3 \# \text { gear } \\
\text { box }\end{array}$ & $\begin{array}{c}4 \# \text { gear } \\
\text { box }\end{array}$ & $\begin{array}{c}5 \# \text { gear } \\
\text { box }\end{array}$ & $\begin{array}{c}\text { Averag } \\
\text { e value }\end{array}$ \\
\hline 40 & 2.14 & 2.20 & 2.00 & 2.05 & 2.10 & 2.10 \\
50 & 2.05 & 2.12 & 1.94 & 1.94 & 1.98 & 2.01 \\
58 & 1.95 & 1.98 & 1.90 & 1.89 & 1.93 & 1.93 \\
70 & 1.90 & 1.93 & 1.86 & 1.82 & 1.83 & 1.87 \\
\hline
\end{tabular}

Oil pressure test is undergo when the inlet oil temperature is respectively $40^{\circ} \mathrm{C} 、 50^{\circ} \mathrm{C} 、 58^{\circ} \mathrm{C} 、 70^{\circ} \mathrm{C}$ through the control water quantity of cooler of control system. Oil pressure of different oil temperature is shown as table4. We can see from the table that oil pressure decreased slowly with the increasing of the oil temperature; Maximum deviation is $2.14 \%$.

\section{Conclusion}


(1) We established the CFD finite analysis model of internal flow passage of regulating valve, and calculated the internal field of regulating valve of different opening degree, oil temperature and flow rate.

(2) We select 10 same type gear boxes and make research on the characteristics of oil temperature on the condition of different opening degree and oil temperature.

(3) There is an relative error between the test data and calculating value when the flow rate is respectively $370 \mathrm{~L} / \mathrm{min} 、 630 \mathrm{~L} / \mathrm{min}$. It meets the requirement of the engineer because the relative error is $5.70 \%$.

(4) The maximum deviation between the average value of different oil temperature and test data is $2.14 \%$; The maximum deviation between the average value of different inlet flow quantity and test data is $2.66 \%$ 。

(5) The deviation of test and simulation is within the permitted error range of the engineer. It proves that test and simulation are reasonable.

\section{References}

[1] China Classification Society. Rules for classification of sea-going steel ships,2006

[2] Jianwen Qin, Liang Zhong. GW series marine gear box clutch engagement process dynamic analysis, Transmission technology, 1991,(2): 17-21

[3] Asghar Alizadehdakhel, Masoud Rahimia,etc.CFD and experimental studies on the effect of valve weight on performance of a valve tray column [J]. Computers and Chemical Engineering,2010,34:1-8.

[4] Sumio Saito,Masahiro Shibata,Hideo Fukae,et. Computational Cavitation Flows at Inception and Light Stages on an Axial-Flow Pump Blade and in a Cage-Guided Control Valve[J]. Fuel Processing Technology,2007,16(4):337-345.

[5] Li Z, Wei Z J, Zhang P. Internal flow field numerical calculation and dynamic characteristic study of pressure-regulating valve[J]. Transaction of Beijing Institute of Technology, 2007, 5(5): 390-394.

[6] Hongxia Lei ,Quan Long. Hydraulic poppet valve of the three-dimensional flow field numerical simulation and visual analysis of [J]. mechanical science and technology,2006,4(4): 426-429.

[7] Gao H, Lin W L, Fu X, et. Suppression of a cavitation near the orifice of a relief valve[J]. Chinese Journal of Mechanical Engineering, 2005, 1(8): 149-155.

[8] Oshima S, Leino T, Linjama M. Experimental study on cavitation in Water hydraulic poppet valve[J]. Transactions of the Japan Fluid Power System Society. 2002, 33(2): 29-35. 